\title{
Keanekaragaman Lumut di Kawasan Cagar Alam Dungus Iwul, Jasinga, Jawa Barat
}

\author{
Moss Diversity in Dungus Iwul Nature Reserve, Jasinga, West Java \\ Florentina Indah Windadri \\ Bidang Botani, Pusat Penelitian Biologi - LIPI, Cibinong Science Centre \\ Jl. Raya Jakarta Bogor KM 46 Cibinong, Bogor, Jawa Barat \\ E-mail: floren_windadri@yahoo.co.id; herbogor@indo.net.id
}

\begin{abstract}
Exploration and collection of the mosses species in Dungus Iwul Nature Reserve were conducted. Thirty eight species including 26 genera and 11 families were recorded. Three species had categories as endemic species i.e Fissidens teysmannianus and Orthomnion javense as endemic species in Java and Hyophila javensis as endemic species in Malesia. Ctenidium lychnites was recorded also as new species record in Java.
\end{abstract}

Key words: Mosses, diversity, nature reserve, Java

\begin{abstract}
Abstrak
Eksplorasi dan koleksi lumut daun (mosses) di Cagar Alam Dungus Iwul telah dilakukan. Tiga puluh delapan jenis lumut yang termasuk dalam 26 marga dan 11 suku telah ditemukan. Tiga jenis diantaranya mempunyai kategori (berstatus) sebagai jenis endemik yaitu Fissidens teysmannianus and Orthomnion javense merupakan jenis endemik di Jawa dan Hyophila javensis sebagai jenis endemik di kawasan Malesia. Sedangkan Ctenidium lychnites dicatat sebagai rekaman baru untuk lumut di Jawa.
\end{abstract}

Kata kunci: Lumut, keanekaragaman, cagar alam, Jawa

Diterima: 26 Januari 2010, disetujui: 21 September 2010

\section{Pendahuluan}

Hutan merupakan salah satu aset penting bagi kehidupan umat manusia di bumi ini. Salah satu fungsinya adalah sebagai tempat penyimpan keanekaragaman hayati dan sumber plasma nutfah yang teramankan khususnya di kawasan konservasi. Namun, keberadaan hutan dewasa ini banyak mengalami tekanan dan ancaman dalam berbagai bentuk yang mengakibatkan degradasi. Adanya degradasi hutan ini merupakan salah satu faktor utama penyebab terjadinya perubahan iklim global. Selain itu juga penciutan kawasan hutan akan berdampak pada kehilangan atau kepunahan berbagai jenis atau penurunan keanekaragaman hayati di muka bumi ini (Windadri, 2008).

Cagar Alam Dungus Iwul merupakan salah satu kawasan konservasi di bagian utara Jawa Barat yang berupa hutan dataran rendah. Luas kawasan konservasi ini sekitar 9 hektar dengan tumbuhan iwul (Orania sylvicola) sebagai jenis dominan. Kawasan cagar alam ini rawan terhadap kerusakan karena lokasinya yang berdekatan dengan jalan raya, di antara perkebunan kelapa sawit dan daerah pemukiman. Oleh karena itu diperlukan pengawasan yang ketat terutama mempertahankan habitat iwul yakni jenis palem yang khas Jawa Barat dan biota lain di dalamnya.

Penelitian keragaman tumbuhan tinggi dan ekologinya di Cagar Alam Dungus Iwul pernah dilakukan (Riswan, 1975 dan Dengjel, 1993). Namun, penelitian lumut daerah ini belum pernah diungkap. Hal ini dapat diketahui dengan belum adanya koleksi spesimen herbarium yang tersimpan di Herbarium Bogoriense maupun laporan-laporan yang menyebutkan keragaman dari tumbuhan rendah di kawasan ini. Kehadiran dan kelangsungan hidup lumut sangat dipengaruhi oleh faktor lingkungan khususnya lingkungan mikro 
meliputi suhu, kelembaban dan pencahayaan. Lumut umumnya berkembang pada daerah pegunungan yang memiliki kelembaban tinggi, suhu rendah dan cukup sinar matahari. Kehadiran lumut di daerah dataran rendah umurnya terbatas pada tempat-tempat lembab seperti pinggir sungai dan daerah sekitar sumber air. Oleh karena itu, perubahan terhadap lingkungan mikro dari suatu tempat akan berdampak cukup besar terhadap keberadaan lumut di lingkungan sekitarnya. Kawasan cagar alam ini sangat rentan terhadap kerusakan lingkungan dan didukung belum adanya data lumutnya maka pendataan terhadap lumutnya sangat diperlukan (Windadri, 2008).

Penelitian ini bertujuan menginventarisasi keanekaragaman lumut daerah kajian. Hasil inventarisasi ini diharapkan akan menambah informasi dan dapat sebagai data pendukung penelitian yang terkait dengan lumut.

\section{Metode Penelitian}

Lokasi penelitian berada di kawasan Cagar Alam Dungus Iwul. Kawasan ini terletak berdekatan dengan jalan raya Bogor Rangkasbitung Desa Cigelung, Kecamatan Jasinga, Kabupaten Bogor, Propinsi Jawa Barat. Secara geografi cagar alam ini berada pada posisi $6^{\circ} 31^{\prime} 00^{\prime \prime}$ LS dan $106^{\circ} 26^{\prime} 00^{\prime \prime}$ BT dengan topografi datar (kemiringan $8-15 \%$ ) dan ketinggian $175 \mathrm{~m}$ di atas permukaan laut. Kawasan Cagar Alam Dungus Iwul mempunyai tipe iklim A dengan curah hujan rata-rata 3.348 mm pertahun dan kelembaban berkisar $70-80 \%$ pada bagian yang agak terbuka dan mencapai $100 \%$ pada bagian yang tertutup rapat oleh semai iwul, temperaturnya berkisar $22,5^{\circ} \mathrm{C}-$ $33^{\circ} \mathrm{C}$. Jenis tanahnya podsolik merah kuning dengan tekstur berpasir sampai lempung berliat (Supraptohardjo, 1963).

Eksplorasi dan koleksi keanekaragaman tumbuhan lumut dilakukan berdasarkan metode Cornard (1982) dan (Rugayah et al., 2004), yaitu dengan menjelajahi seluruh area hutan yang diteliti. Semua jenis lumut yang dijumpai dikumpulkan, diberi nomor dan dicatat data lapangannya. Data lapangan yang diperlukan antara lain habitat, substrat, ketinggian tempat, dan kegunaannya (jika ada). Di samping itu juga dicatat data morfologinya, antara lain warna, tipe kaliptra (jika ada), dan posisi kapsul. Dalam pengambilan spesimen diusahakan selengkap mungkin yang meliputi fase atau generasi gametofit (tumbuhan lumutnya sendiri) maupun generasi sporofit (bagian yang menghasilkan spora). Spesimen lumut yang dikoleksi kemudian dikeringanginkan, dan selanjutnya dibuat herbarium serta diidentifikasi nama jenisnya. Beberapa buku acuan yang digunakan dalam identifikasi antara lain 'A Handbook of Malesian Mosses' (Eddy, 1988 dan 1990), 'Mosses of The Philippines' (Bartram, 1939), 'Mosses and Liverworts of Hong Kong'(So, 1995). Di samping itu juga dilakukan pengecekan silang hasil identifikasi dengan spesimen koleksi yang tersimpan di Herbarium Bogoriense. Lumut yang telah diketahui namanya dengan benar diproses lebih lanjut sebagai koleksi dan disimpan di Herbarium Bogoriense.

\section{Hasil dan Pembahasan}

\section{Hubungan antara Habitat dengan Keanekaragaman Lumut di Lokasi Penelitian}

Berdasarkan hasil pengamatan di lapangan dapat diketahui bahwa tumbuhan lumut umumnya banyak ditemukan tumbuh melimpah pada tempat-tempat yang teduh dan lembab terutama di tepi-tepi sungai. Apabila, ditinjau dari substrat untuk pertumbuhannya maka lumut di lokasi penelitian umumnya tumbuh di pohon $(19$ jenis $=51 \%$, Tabel 1$)$. Keadaan seperti ini karena permukaan pohon atau ranting umumnya tidak rata sehingga spora-spora lumut yang lepas dari kotak sporanya dapat tertampung atau tetap menempel pada bagian batang yang retak-retak tersebut. Apabila, kondisi lingkungan mendukung maka spora-spora lumutpun akan berkecambah dan dapat meneruskan kehidupannya pada substrat tersebut. Keadaan seperti ini juga pernah dilaporkan oleh Windadri (2009) yang menjelaskan bahwa adanya permukaan perakaran yang retak-retak dan didukung oleh lingkungan yang lembab serta sinar matahari cukup maka kuncup dan spora lumut dapat berkecambah dan meneruskan kehidupannya Di samping itu pada bagian daun pepohonan juga sering ditemukan pertumbuhan lumut ini terutama pada bagian daun-daun yang 
kasar atau berbulu serta di lingkungan yang lembab (di tepi sungai) dan teduh.

Selain di pohon lumut di hutan dataran rendah umumnya juga banyak ditemukan tumbuh di tanah ataupun kayu-kayu lapuk. Kedua substrat ini merupakan tempat yang baik untuk pertumbuhan lumut karena keduanya mampu menyediakan air maupun zat-zat yang diperlukan untuk pertumbuhannya. Namur, di lokasi penelitian lumut yang bersubstrat kayu lapuk ternyata paling sedikit (20\%) ditemukan, hal ini diakibatkan oleh kondisi hutan yang umumnya didominasi pohon iwul yang permukaan batangnya relatif halus sehingga batang-batang pohon iwul yang robohpun juga tidak dapat sebagai substrat untuk pertumbuhannya. Lumut yang ditemukan tumbuh di kayu lapuk umumnya berasal dari jenis-jenis pohon selain pohon iwul.

\section{Keanekaragaman Lumut di Lokasi Penelitian}

Dari hasil penelitian dapat diketahui bahwa tumbuhan lumut yang berhasil dikoleksi tercatat 112 nomor. Berdasarkan hasil identifikasinya dapat dikelompokkan menjadi 38 jenis, yang termasuk kedalam 26 marga dan 11 suku. Untuk membedakan antara jenis lumut yang satu dan lainnya dapat diketahui melalui kekhasan yang ada pada tiap-tiap jenisnya (Lampiran 1).

Apabila diamati lebih teliti terhadap jenisjenis lumut yang ditemukan di lokasi penelitian tampak bahwa beberapa jenis lumut mempunyai kepentingan tersendiri baik dari segi status maupun kepentingan yang lain (Tabel 2).

Berdasarkan Tabel 2, dapat diketahui bahwa lumut yang ditemukan dominan di lokasi penelitian tergolong dalam kelompok suku Calymperaceae Leucophanes glaucum (Schwegr) Mitt. dan Mitthyridium flavum (C. Mull) Robinson). Suku Calymperaceae merupakan satu kelompok lumut tropis yang tumbuh di dataran rendah dan hutan-hutan sekitar pantai (Reese, 1978b). Substrat pertumbuhannya secara umum berupa batang pohon, batuan atau tanah (Ellis et al., 1999). Anggota suku ini tumbuh tegak atau menjalar, membentuk bantalan. Daunnya berdinding tebal dan berkosta. Kosta terdiri dari dua lapisan pita stereid terletak di bagian dorsal dan ventral, berfungsi sebagai penyokong sel-sel berklorofil. Adanya sifat daun demikian memungkinkan anggota kelompok lumut ini dapat menyimpan air di dalam lapisan stereidnya sebagai cadangan di saat kering. Perkembangbiakan generatifnya menggunakan spora yang tersimpan dalam kotak spora. Kotak spora dihasilkan oleh generasi sporofit yang terletak di ujung individunya. Selain itu juga dapat berkembang biak secara vegetatif dengan menghasilkan kuncup-kuncup (gemma) halus di ujung daunnya. Kuncup (gemma) biasanya terbentuk untuk menyesuaikan diri pada kondisi kering dan panas (Yamaguchi et al., 2005). Dengan dimilikinya dua macam alat perkembangbiakan pada suku Calymperaceae maka dimungkinkan persebaran dan populasinya akan lebih besar dibandingkan dengan kelompok suku-suku lainnya.

Dua jenis lumut yang ditemukan di lokasi penelitian yaitu Fissidens teysmannianus dan Orthomnium javense pernah dilaporkan sebagai jenis endemik di Jawa (Eddy, 1988 dan 1996). Di lokasi penelitian Fissidens teysmannianus (FIW 2140) ditemukan tumbuh di berbagai substrat mulai dari bebatuan, tanah, kayu lapuk hingga pohon. Jenis ini dilaporkan oleh Eddy (1988) tumbuh di tempat teduh pada batuan yang lembab, dengan demikian terjadi perluasan substrat pertumbuhan bagi jenis ini. Adapun Orthomnium javense (FIW 2358) di lokasi penelitian ditemukan tumbuh pada substrat berupa tanah atau batu cadas. Selain kedua jenis lumut di atas ditemukan juga satu jenis lumut (Hyophila javanica, FIW 2357) yang dilaporkan sebagai jenis endemik di kawasan Malesia khususnya Sumatra, Jawa dan pulau-pulau di sekitarnya (Eddy, 1990).

Disamping jenis-jenis yang endemik di dalam penelitian ini juga ditemukan satu jenis lumut yang berstatus sebagai rekaman baru ('new record') bagi Pulau Jawa yaitu Ctenidium lychnites (FIW 2327). Penentuan jenis ini sebagai rekaman baru untuk Pulau Jawa didasarkan hasil penelusuran pustaka terkait yang menyatakan bahwa jenis ini tersebar di Filipina, Khasia, Nilghiri, Sri Lanka (Bartram, 1939). Pada pengecekan silang dengan spesimen koleksi yang tersimpan di Herbarium Bogoriense tidak ditemukan koleksi dari jenis ini yang berasal dari Pulau Jawa, koleksi yang ada berasal dari Flores (A. Touw dan M Snoek, nomor 23022, 233141, 22867). Pada penelusuran 
pustaka yang terkait dengan lumut dari jenis Barbella enervis dilaporkan bahwa jenis ini mempunyai daerah persebaran meliputi Himalaya, Sri Lanka, Filipina, Australia, Pulau Lord Howe, New Caledonia (Bartram, 1939). Pada pengecekan silang dengan spesimen koleksi Herbarium Bogoriense ternyata jenis ini pernah dikoleksi dari Jawa oleh beberapa kolektor antara lain Himmah (nomor 282), F.I. Windadri (nomor FIW 2127 dan 2138) Fleischer (nomor 231) dan W Meijer (nomor B.818.K). Di
Irian pernah dikoleksi oleh U. Hapid (nomor 14). Meskipun telah dilakukan koleksi dan identifikasinya laporan tentang keberadaannya di Indonesia belum pernah ada. Keadaan ini dapat terjadi oleh karena spesimen koleksi merupakan hadiah dari peneliti lain dan tidak pernah dipublikasikan serta hanya disimpan sebagai koleksi herbarium. Dengan demikian dapat dilaporkan bahwa terjadi perluasan daerah persebaran dari jenis Barbella enervis.

Tabel 1. Hubungan antara tipe substrat dan jumlah keragaman lumut di Cagar Alam Dungus Iwul, Jasinga, Bogor, Jawa Barat.

\begin{tabular}{|c|c|c|}
\hline No & Tipe Habitat & "Jumlah Jenis Lumut \\
\hline 1 & Batang pohon & 19 \\
\hline 2 & Akar & 10 \\
\hline 3 & Tanah & 13 \\
\hline 4 & Bebatuan & 15 \\
\hline 5 & Kayu lapuk & 8 \\
\hline
\end{tabular}

Tabel 2. Beberapa jenis lumut penting di Cagar Alam Dungus Iwul, Jasinga, Bogor, Jawa Barat

\begin{tabular}{|c|c|c|c|}
\hline Jenis & Suku & Tingkat kepentingan & Tipe Habitat \\
\hline $\begin{array}{l}\text { Leucophanes glaucum (Schwegr.) } \\
\text { Mitt. dan Mitthyridium flavum (C. } \\
\text { Mull) Robinson }\end{array}$ & Calymperaceae & dominan di lokasi penelitian & $\begin{array}{l}\text { Akar, batang, kayu } \\
\text { lapuk }\end{array}$ \\
\hline Hyophila javanica (Nees.) Brid. & Pottiaceae & $\begin{array}{l}\text { Endemik di Malesia (Jawa, Sumatra } \\
\text { dan pulau-pulau di sekitarnya) }\end{array}$ & Bebatuan \\
\hline Orthomnion javense (Fleisch.) Kop. & Mniaceae & Endemik di Jawa & Tanah, bebatuan \\
\hline $\begin{array}{l}\text { Fissidens teysmannianus Dozy \& } \\
\text { Molk. }\end{array}$ & Fissidentaceae & Endemik di Jawa & $\begin{array}{l}\text { bebatuan, tanah, kayu } \\
\text { lapuk hingga pohon }\end{array}$ \\
\hline Ctenidium lychnites (Mitt.) Broth. & Hypnaceae & Rekaman baru bagi Pulau Jawa & Batang pohon \\
\hline Barbella enervis (Mitt.) Fleisch. & Meteoriaceae & Perluasan daerah persebaran & Batang pohon \\
\hline
\end{tabular}

\section{Simpulan dan Saran}

\section{Simpulan}

Ditemukannya 38 jenis lumut di kawasan hutan Cagar Alam Dungus Iwul dengan luas area yang relatif sempit (9 HA) menunjukkan bahwa keanekaragaman jenisnya tergolong tinggi. Kondisi lingkungan cagar alam yang masih baik dan terjaga serta kekhasan hábitatnya mampu mempertahankan keberadaan jenis-jenis lumut endemik. Adanya penemuan jenis-jenis lumut yang berstatus sebagai rekam baru (Ctenidium lychnites) dan perluas daerah sebaran (Barbella enervis).

\section{Saran}

Meskipun Cagar Alam Dungus Iwul mempunyai luasan yang sempit keberadaannya sangat berarti bagi dunia ilmu pengetahuan karena kawasan cagar alam ini merupakan hábitat khusus untuk pohon iwul (Orania sylvicola) dan beberapa jenis lumut endemik Jawa serta mampu mempertahankan kehidupan beberapa jenis lumut yang bukan berasal dari Jawa. Di samping itu keberadaannya diantaran perkebunan kepala sawit akan sangat membantu mempertahankan ketersediaan air tanah bagi masyarakat di sekitarnya. Oleh karena itu, kelestarian dan statusnya sebagai cagar alam disarankan tetap dipertahankan, meskipun luasannya sangat kecil janganlah keberadaannya diabaikan. Keikutsertaan beberapa orang anggota masyarakat sebagai pamswakarsa juga tetap dipertahankan untuk menumbuhkan rasa mencintai dan memiliki serta tanggung jawab dalam menjaga kelestariannya. 


\section{Ucapan Terima Kasih}

Penulis mengucapkan terima kasih kepada Bapak pimpinan DIKTI beserta jajarannya selaku penyandang dana pada kegiatan penelitian ini. Demikian pula kepada Kepala Pusat Penelitian Biologi LIPI beserta jajarannya yang telah memberi kepercayaan dan kesempatan untuk melakukan kerja sama penelitian ini, serta Kepala BKSDA wilayah Jawa Barat beserta staf dan jajarannya yang telah memberikan izin dan segala fasilitasnya. Tak lupa ucapan terima kasih kepada Bapak Drs. Tahan Uji staf senior di Pusat penelitian BiologiLIPI yang telah memberikan masukan dan saran untuk penyempurnaan tulisan ini. Terima kasih juga kepada semua fihak yang telah membantu kelancaran selama melakukan kegiatan penelitian hingga selesainya penelitian ini.

\section{Daftar Pustaka}

Bartram, E.B. 1939. Mosses of the Philippines. The Philippine J. of science, 68: 1-423.

Conard, H.S. 1982. How to know Mosses and Liverworts. Second editions. Wm.C. Brown Company Publishers. Dubuque, Iowa. 302 halaman.

Dengjel, H. 1993. Composition, Structure and Dynamic Aspects of A tropical Lowland Rain Forest Patch in West Java, Preserved in The Nature Reserve of Dungus Iwul, Jasinga, Indonesia. A Thesis of the Institute Research and Development Centre for Biology, Indonesian Institute for Science (LIPI) to the Faculty of Biology-Chemistry of Friedrich-AlexanderUniversity Erlangen- Nurnberg.

Eddy, A. 1988. A Handbook of Malesian Mosses Volume 1 (Sphagnales to Dicranales). The Natural History Museum. London.
Eddy, A. 1990. A Handbook of Malesian Mosses Volume 2 (Leucobryaceae to Buxbaumiaceae). The natural History Museum. London.

Eddy, A. 1996. A Handbook of Malesian Mosses Volume 3 (Sphlaghnaceae to Leptostomataceae) The Natural History Museum. London.

So, M.L. 1995. Mosses and Liverworts of Hong Kong volume 1 . Heavenly People Depot. 162 halaman + i-viii.

Ellis, L.T. dan Tan, B.C. 1999. The Moss family Calymperaceae (Musci) in the Philippnes. Bull. Nat. Hist. Musc. Lond. (Bot.), 29 (1): 1-46.

Reese, W.D. 1978b. World ranges, implications for patterns of historical dispersal and speciations, and comments on phylogeny of Syrrhopodon (Calymperaceae). Memoirs of the New York Botanical Garden, 45: 426-445.

Riswan, S. 1975. Vegetasi Hutan di Cagar Alam Dungus Iwul, Jasinga, Bogor. Kertas kerja konggres Biologi II \& Seminar Biologi IV, 10-12 Juli 1975, Jogjakarta.

Rugayah, Retnowati, A., Windadri, F.I. dan Hidayat, A. 2004. Pengumpulan data Taksonomi. Dalam Rugayah, E.A. Widjaja, Praptiwi (Eds.). Pedoman Pengumpulan Data Keanekaragaman Flora. Pusat Penelitian Biologi- Lembaga Ilmu Pengetahuan Indonesia.

Supraptohardjo, M. 1963. Peta Tanah Tinjau Djawa Barat. Lembaga Penelitian Tanah, Bogor.

Windadri, F.I. 2008. Keanekaragaman Jenis Lumut (Musci) di Lereng Gunung Wani, Suaka Margasatwa Buton Utara, Sulawesi Tenggara. Biota, 13 (2): 106-120.

Windadri, F.I. 2009. Keragaman Lumut Pada Marga Pandanus Di Taman Nasional Ujung Kulon, Banten. J. Natur Indonesia, 12 (20): 89-93.

Yamaguchi, T., Windadri, F.I., Haerida, I., Simbolon, H., Kunimura, A., Miyawaki, H. dan Shimizu, H. 2005. Effects of forest fires on Bryophyte Flora in East Kalimantan, Indonesia. Phyton, 45 (4): 561-569. 
Lampiran 1. Daftar Jenis Lumut di Cagar Alam Dungus Iwul beserta Ciri Khasnya.

\begin{tabular}{|c|c|c|}
\hline No. & Nama Suku / Jenis & Ciri Khas \\
\hline & CALYMPERACEAE: & \\
\hline 1. & Calymperes boulayi Besch. & $\begin{array}{l}\text { Reseptakel terbentuk perlahan-lahan mulai dari helaian daun di atas } \\
\text { sel-sel jernih (cancellinae) hingga ke ujung daun }\end{array}$ \\
\hline 2. & Calymperes afzelii Sw. & $\begin{array}{l}\text { Teniol terdiri dari } 4 \text { deret sel-sel jernih atau lebih yang berdinding } \\
\text { tipis }\end{array}$ \\
\hline 3. & Calymperes palisotii Schwaegr. & Teniol terdiri dari $1-2$ deret sel-sel jernih \\
\hline 4. & Calymperes schmidtii Broth. & $\begin{array}{l}\text { Panjang daun berkuncup } 2 \text { kali atau lebih dari daun normal, } \\
\text { kadang-kadang melebar di bagian ujung }\end{array}$ \\
\hline 5. & Leucophanes glaucum (Schwegr) Mitt. & $\begin{array}{l}\text { Daun mempunyai } 3-4 \text { lapisan sel leukosis dan ujungnya } \\
\text { membentuk seperti saluran. }\end{array}$ \\
\hline 6. & Leucophanes massartii Ren \& Card. & $\begin{array}{l}\text { daunnya mempunyai } 2 \text { lapisan sel leukosis dan ujung daunnya } \\
\text { mendatar (Flat). }\end{array}$ \\
\hline 7. & Mitthyridium flavum (C. Mull) Robinson & $\begin{array}{l}\text { Sel-sel kosong berukuran besar dan mendominasi pangkal daun, } \\
\text { sel-sel leukosis persegi, berlubang besar di luarnya. }\end{array}$ \\
\hline 8. & $\begin{array}{l}\text { Syrrhopodon muelleri (Dozy \& Molk.) } \\
\text { Lac. }\end{array}$ & $\begin{array}{l}\text { Sel-sel lamina berkhlorofil, sel-sel pembatas terdiri atas sel-sel } \\
\text { memanjang }\end{array}$ \\
\hline
\end{tabular}
DICRANACEAE:

9. Campylopus involutus (C.Mull.) Jaeg.

10. Microdus miquelianus (Mont.) Bescher. FISSIDENTACEAE:

11. Fissidens braunii (C. Mull.) Dozy \& Molk

12. Fissidens gedehensis Fleisch

13. Fissidens perpusillus Wils. ex. Mitt.

14. Fissidens teysmannianus Dozy \& Molk. *

15. Fissidens zippelianus Dozy \& Molk.

\section{HOOKERIACEAE:}

16. Callicostella papillata (Mont.) Mitt

17. Callicostella prabaktiana (C. M.) Lac.

18. Chaetomitrium papillifolium Lac.

19. Chaetomitrium philippinense (Mont.) Lac. HYPNACEAE:

20. Ctenidium lychnites (Mitt.) Broth. \#

21. Isopterygium bancanum (Lac.) Jaeg.

22. Isopterygium minutirameum (C. Mull) Jaeg

23. Vesicularia montagnei (Bel.) Fleisch.

OCTOBLEPHARACEAE:

24. Octoblepharum albidum Hedw. METEORIACEAE:

25. Barbella comes (Griff) Broth.

26. Barbella enervis (Mitt) Fleisch.

27. Floribundaria pseudo floribunda Fleisch.

MNIACEAE:

28. Orthomnion dilatatum (Mitt.) Chen.
Tingginya beberapa milimeter, seta kemerahan

Bagian bawah dari batang tidak berdaun, panjang daun duplikat mencapai $1 / 2$ panjang daun

Tingginya lebih dari $10 \mathrm{~mm}$, sporofit terminal

Tumbuhan kadang bercabang, tingginya kurang dari $10 \mathrm{~mm}$.

Tingginya lebih dari $10 \mathrm{~mm}$, sporofit lateral

Daun ditemukan disepanjang tubuhnya, panjang daun duplikat mencapai $1 / 2$ panjang daun

Ujung daun bergigi tak beraturan. Sel-sel lamina tak beraturan, memanjang ke arah pangkal daun, sudut selnya berpapila.

Ujung daunnya bergerigi kecil, sel-sel laminanya berbentuk herksagonal dan halus

Tumbuhan kecil, daun cabang kurang dari $1 \mathrm{~mm}$

Tumbuhan besar dan kaku, panjang daun cabang 1,5-2 mm.

Daun batang dan cabang berbeda, tepi bergerigi kuat, sel-sel alar persegi

Daun-daun cabang membulat,tepinya bergerigi

Daun-daun cabang memanjang,berumah satu (autoicous)

Daun berkerut dan melengkung jika kering, melebar dan pipih jika basah, cembung, meruncing pendek ujungnya. Daun cabang lebih kecil dari daun batang

Tinggi kurang dari $2 \mathrm{~cm}$, Daun mengkilat, tampak agak tebal

Tubuh mengkilat, ujung percabangan tidak berbentuk rambu

Tubuh mengkilat, ujung percabangan seperti rambut

Tubuh kekar, daun batang lebih panjang dari F. floribundaria, berbentuk segitiga memanjang, pangkal menjantung. Daun cabang meramping

Sel-sel pembatas berakhir hingga pertengah daun atau kadang 
29. Orthomnion javense (Fleisch.) Kop. * NECKERACEAE:

30. Pinnatella anacamptolepis (C. M.) Broth. POTTIACEAE :

31. Hyophila javanica (Nees.) Brid. *

32. Scopelophila cataractae (Mitt.) Broth SEMATOPHYLLACEAE:

33. Acroporium lamprophyllum Mitt.

34. Clastobryella cuculligera (Lac.) Fleisch.

35. Sematophyllum saproxylophilum (C. Mull.) Fleisch.

36. Taxithelium kerianum (Broth.) Fleisch.

37. Taxithelium lindbergii (Lac.) Ren \& Card

38. Trichosteleum boschii (Doz. \& Molk.) Jaeg. ditemukan hingga ujungnya

Sel-sel pembatas ditemukan hanya di pangkal.

Daun-daun batang asimetris, daun-daun cabang berukuran lebih kecil

Tinggi mencapai $5 \mathrm{~mm}$. Kapsul asimetris, tutupnya mengerucut berparuh

Daun seperti lidah. Sel-sel lamina bagian bawah membesar dekat kosta, membentuk zona jernih

Daun membulat telur- lanset, menjantung di pangkal, ujung bergigi Daun tidak berkosta, bergerigi tajam di ujung. Sel-sel alar berwarna Daun tersebar tegak, cembung. Sel-sel daun memanjang, halus, sel alar memipih.

Daun asimetris, tepi daunnya rata

Daun asimetris, tepi daun bergerigi tajam

Berukuran besar, hijau kekuningan. Batang coklat tua. Ujung daun bergelombang. Sel-sel alar coklat kemerahan

Keterangan: Status :* ${ }^{*}$ jenis endemik; \# : catatan baru (New Record) 